\title{
Minerais séricos, características morfométricas ósseas e deposição de minerais ósseos de frangos de corte alimentados com dieta com inclusão de bentonita
}

\author{
[Serum minerals, bone morphometric characteristics and deposition of bone minerals from \\ broilers fed diet containing bentonite] \\ A.F. Schneider ${ }^{1}$, J.K. Mayer ${ }^{1}$, J.Volpato ${ }^{1}$, C.E. Gewehr ${ }^{2}$ \\ ${ }^{1}$ Aluno de pós-graduação - Universidade do Estado de Santa Catarina - Lages, SC \\ A.F. Schneider1 \\ https://orcid.org/0000-0002-1747-2819 \\ htps://orcid-org/0000-0001-8700-5426 \\ J.Volpatol \\ holpato1 \\ C.E. Gewehr2 \\ https://orcidorg/0000-0002-1590-0242
}

${ }^{2}$ Universidade do Estado de Santa Catarina - Lages, SC

\section{RESUMO}

O objetivo deste trabalho foi avaliar a concentração sérica de cálcio, cloretos, ferro, fósforo e magnésio, as características morfométricas ósseas e a deposição de cálcio e fósforo nas tíbias de frangos de corte recebendo dieta com zero, 0,25 ou $0,50 \%$ de bentonita. Um ensaio foi conduzido com 288 frangos de corte de 14 a 21 dias de idade, submetidos a três dietas experimentais: sem inclusão $(0,0)$; com inclusão de 0,25 e com inclusão de $0,50 \%$ do adsorvente bentonita. Não foram observadas diferenças $(P>0,05)$ no desempenho das aves, nos níveis séricos de cálcio, cloretos, ferro e magnésio, no entanto os níveis de fósforo foram reduzidos $(\mathrm{P}<0,05)$ nas aves que ingeriram dieta com $0,50 \%$ de bentonita. Em relação às tíbias, observou-se redução $(\mathrm{P}<0,05)$ na matéria mineral $(\mathrm{g}$ e \%) e no teor de cálcio com a inclusão de $0,50 \%$ de bentonita. Houve redução $(\mathrm{P}<0,05)$ nos níveis de fósforo das tíbias com a inclusão de 0,25 e $0,50 \%$ de bentonita. Conclui-se que a inclusão de até $0,50 \%$ do adsorvente de micotoxinas bentonita na dieta de frangos de corte não altera o desempenho zootécnico das aves. A inclusão de $0,25 \%$ de bentonita, na dieta de frangos de corte, não altera a concentração dos minerais séricos e a deposição de minerais nas tíbias, entretanto a inclusão de $0,5 \%$ reduz os níveis séricos de fósforo, o teor de matéria mineral e a concentração de cálcio e fósforo ósseos, sem afetar as características morfométricas ósseas.

Palavras-chave: aditivos antimicotoxinas, cálcio, fósforo

\begin{abstract}
The aim of this study was to evaluate performance, serum concentration of calcium, chloride, iron, magnesium, phosphorus, and bone characteristics, ash, calcium, and phosphorus in tibias of broilers receiving diet with zero, 0.25 or $0.50 \%$ of bentonite. No differences were found on performance of poultry, on serum mineral calcium, chloride, iron, magnesium, however phosphorus levels of broilers fed on diets containing $0.5 \%$ bentonite was reduced. With respect to tibia, reduction was observed on mineral matter ( $g$ and \%) and calcium levels with inclusion of $0.50 \%$ bentonite, and reduction on phosphorus levels with inclusion of 0.25 or $0.50 \%$ of bentonite on diet. We conclude that the inclusion of up to $0.50 \%$ of mycotoxin adsorbent bentonite in diet of broiler does not change broiler performance. The inclusion of $0.25 \%$ of bentonite in diet of broiler does not change serum mineral concentration and mineral deposition; however, the inclusion of $0.5 \%$ decrease serum levels of phosphorus, the content of bone mineral matter, with not effects on bone morphometric characteristics.
\end{abstract}

Keywords: anti-mycotoxins additives, calcium, phosphorus

\section{INTRODUÇÃO}

A contaminação dos alimentos por micotoxinas é um desafio frequente à sanidade animal, já que

Recebido em 16 de abril de 2017

Aceito em 13 de novembro de 2017

E-mail: aline_schneider@hotmail.com interfere negativamente no metabolismo das aves, podendo levar à mortalidade expressiva e a um grande impacto econômico. Além disso, as micotoxinas podem se depositar no tecido muscular das aves e, consequentemente, entrar na cadeia alimentar humana por meio do 
consumo de carnes, apresentando-se como um risco à saúde pública (Maziero; Bersot, 2010).

O maior problema causado pelas dietas contaminadas por micotoxinas não são os episódios de doenças agudas, e sim as baixas doses ingeridas por longo período, que provocam diversas desordens metabólicas, reduzindo consideravelmente o aproveitamento dos nutrientes e como consequência, os índices de produtividade (Bryden, 2012).

Para controle das micotoxinas, os adsorventes ou aditivos antimicotoxinas vêm sendo incluídos nas dietas animais com o intuito de ligarem-se às micotoxinas no intestino, impedindo sua absorção. As bentonitas, minerais argilosos da família das esmectitas, são amplamente utilizadas na avicultura em virtude de seu baixo custo e eficácia na adsorção a micotoxinas, com seu efeito profilático consistindo na ligação às micotoxinas de forma irreversível no nível intestinal, impedindo sua absorção através do epitélio (Indresh et al., 2013).

Haja vista a capacidade química dos adsorventes de se ligarem às micotoxinas, alguns autores atentam para a possibilidade de uma possível ligação com minerais, já que nutrientes de alto peso molecular podem ser carreados por esses aditivos, tornando-os indisponíveis para absorção (Southern et al., 1994). Estudos vêm demonstrando a interação das argilas na digestibilidade de nutrientes e, se as inclusões destas forem elevadas, elas podem se ligar a minerais e a antibióticos, como a monensina (Gowda et al., 2013).

$\mathrm{Na}$ presença de bentonita, relata-se redução na absorção pelo trato gastrointestinal e menor deposição de cálcio em ratos, o que pode estar relacionado à competição por sítios de ligação na mucosa intestinal, e posterior transporte para o sangue, entre os minerais presentes no lúmen intestinal oriundos da dieta e aqueles ligados à bentonita (Grosicki et al., 2004). Os autores afirmam ainda que as alterações causadas pela presença da bentonita em nível intestinal variam de acordo com o elemento mineral estudado.

Assim, com base na estrutura química e nos mecanismos de adsorção dos aditivos antimicotoxinas, verifica-se uma possibilidade de ligação a vitaminas, minerais, entre outros nutrientes, diminuindo sua disponibilidade para as aves. Nesse âmbito, faz-se necessário estudar a adsorção dos minerais, principalmente cálcio e fósforo, já que são, em quantidade, os mais limitantes para as aves.

Com base no exposto, o objeto do presente trabalho foi avaliar os possíveis efeitos do adsorvente de micotoxinas bentonita sobre a concentração sérica de minerais, as características morfométricas ósseas e a deposição de cálcio e fósforo nas tíbias de frangos de corte recebendo dietas sem e com o aditivo, em doses usuais de inclusão.

\section{MATERIAL E MÉTODOS}

O ensaio foi conduzido no Setor de Avicultura do Centro de Ciências Agroveterinárias, da Universidade do Estado de Santa Catarina, região Sul do Brasil. Foram utilizados 320 frangos de corte, machos, da linhagem Cobb 500, oriundos de incubatório comercial, vacinados contra doença de Marek, bronquite infecciosa e doença de Gumboro. As aves foram recebidas com um dia de idade e alojadas em pinteiro único, com ambiente aquecido na faixa de 30 a $32^{\circ} \mathrm{C}$, sobre cama de maravalha de $8 \mathrm{~cm}$ de altura, recebendo água filtrada e clorada $(5 \mathrm{ppm})$ e ração isonutritiva à vontade, no período de um a 13 dias de idade. As dietas foram formuladas seguindo as recomendações de Rostagno et al. (2011), descritas na Tab. 1.

Aos 14 dias de idade, 288 aves foram transferidas para 24 gaiolas metabólicas, sendo primeiramente pesadas individualmente e separadas por faixa de peso, descartando-se as mais leves e as mais pesadas. A distribuição foi realizada individualmente, conforme recomendações de Sakomura e Rostagno (2007).

A sala de metabolismo continha gaiolas metabólicas $(0,5 \times 0,5 \mathrm{~m})$ de arame galvanizado, as quais eram dotadas de um comedouro tipo calha, dois bicos de bebedouros tipo nipple acoplados a um reservatório individual de água e uma bandeja coletora de excretas. $\mathrm{O}$ ambiente foi climatizado de acordo com a temperatura de conforto para a idade das aves, seguindo-se o manual da linhagem. 
Tabela 1. Composição nutricional e calculada das dietas fornecidas às aves até os 13 dias de idade

\begin{tabular}{|c|c|c|}
\hline Ingredientes $(\mathrm{g} / \mathrm{kg})$ & Pré-inicial (1 - 7 dias) & Inicial ( 8 - 13 dias) \\
\hline Milho & 529,85 & 555,77 \\
\hline Farelo de soja & 395,48 & 365,62 \\
\hline Calcário calcítico & 10,4 & 10,8 \\
\hline Fosfato bicálcico & 19,0 & 15,5 \\
\hline Sal & 4,78 & 4,55 \\
\hline Óleo vegetal & 30,9 & 38,9 \\
\hline Metionina & 1,96 & 1,68 \\
\hline Lisina & 2,62 & 2,18 \\
\hline Premix $^{1}$ & 5,00 & 5,00 \\
\hline Total & 1000 & 1000 \\
\hline \multicolumn{3}{|c|}{ Composição calculada } \\
\hline Energia metabolizável (kcal/kg) & 2960 & 3050 \\
\hline Proteína bruta (\%) & 22,4 & 21,2 \\
\hline Cálcio total (\%) & 0,92 & 0,84 \\
\hline Fósforo disponível (\%) & 0,47 & 0,40 \\
\hline Sódio $(\%)$ & 0,22 & 0,21 \\
\hline Potássio (\%) & 0,88 & 0,83 \\
\hline Cloro $(\%)$ & 0,60 & 0,30 \\
\hline Lisina digestível (\%) & 1,32 & 1,22 \\
\hline Metionina digestível (\%) & 0,52 & 0,47 \\
\hline Treonina digestível (\%) & 0,76 & 0,72 \\
\hline
\end{tabular}

${ }^{1}$ Composição do premix mineral e vitamínico (níveis por kg do produto): vitamina B12 3.000,00mcg, vitamina B6 $622 \mathrm{mg}$, ácido pantotênico $2.934,9 \mathrm{mg}$, niacina $7.500 \mathrm{mg}$, biotina $19 \mathrm{mg}$, vitamina B2 $1.125 \mathrm{mg}$, manganês $16.800 \mathrm{mg}$, zinco $13.000 \mathrm{mg}$, ferro $12.600 \mathrm{mg}$, iodo $250 \mathrm{mg}$, cobre $2.100 \mathrm{mg}$, selênio $75 \mathrm{mg}$, vitamina A $2.640 .000 \mathrm{UI} / \mathrm{kg}$, vitamina D3 638.000UI/kg, vitamina E 3.650UI/kg, vitamina K3 450mg, vitamina B1 502mg, ácido fólico 189mg, colistina $2.500 \mathrm{mg}$, BHT $0,80 \mathrm{~g}$, colina $86,67 \mathrm{~g}$.

Para a composição das dietas experimentais, foram adquiridos $350 \mathrm{~kg}$ de milho oriundo de mesa densimétrica de empresa comercial. O milho recebido foi acondicionado em bandejas de alumínio e levado à estufa a $200^{\circ} \mathrm{C}$ por $90 \mathrm{~min}$. Esse procedimento visou à eliminação/redução das possíveis micotoxinas existentes, seguindose metodologia descrita por Hwang e Lee (2006). $\mathrm{O}$ procedimento foi realizado um dia antes da produção das dietas. Foram formuladas três dietas (tratamentos), de acordo com as recomendações de Rostagno et al. (2011), sendo a primeira dieta controle (sem inclusão) e as demais com inclusão de 0,25 ou $0,50 \%$ de bentonita (Tab. 2).

A bentonita utilizada era composta por $65,4 \%$ de $\mathrm{SiO}_{2}, 17,5 \%$ de $\mathrm{Al}_{2} \mathrm{O}_{3}, 5,10 \%$ de $\mathrm{Fe}_{2} \mathrm{O}_{3}, 2,10 \%$ de
$\mathrm{K}_{2} \mathrm{O}, 1,99 \%$ de $\mathrm{MgO}, 0,71 \%$ de $\mathrm{CaO}$ e $0,52 \%$ de $\mathrm{Na}_{2} \mathrm{O}$ (informações fornecidas pelo fabricante), além de outros compostos em menores quantidades. A recomendação de uso do fabricante é de 2 a $5 \mathrm{~kg} /$ tonelada.

Avaliou-se o desempenho de 14 a 21 dias de idade por meio do peso vivo médio inicial e final (g), do consumo de ração $(\mathrm{g})$, do ganho de peso médio diário $(\mathrm{g})$ e da conversão alimentar $(\mathrm{g} / \mathrm{g})$.

No $21^{\circ}$ dia de idade das aves, procedeu-se à coleta de sangue de cinco aves por repetição, totalizando 120 aves. A coleta de sangue foi realizada mediante punção da veia jugular, com agulhas hipodérmicas 25 x 0,8mm. Coletaram-se $3 \mathrm{~mL}$ de sangue de cada ave, os quais foram imediatamente acondicionados em tubos 
identificados, sem anticoagulante. As amostras foram deixadas em repouso por 40 minutos e, após, foram centrifugadas a 3.500rpm por 10 minutos, obtendo-se o soro. Neste, foi realizada a leitura dos minerais cálcio $(\mathrm{mg} / \mathrm{dL})$, fósforo
(mg/dL), ferro $(\mu \mathrm{g} / \mathrm{dL})$, magnésio $(\mathrm{mg} / \mathrm{dL})$ e cloretos $(\mathrm{mEq} / \mathrm{L})$, utilizando-se o aparelho bioquímico Labmax Plenoo®, por meio de kits comerciais Labtest@.

Tabela 2. Composição nutricional calculada das dietas experimentais, sem inclusão de bentonita (controle) e com inclusão de 0,25 ou 0,50\% de bentonita, em frangos de corte de 13 a 21 dias de idade

\begin{tabular}{|c|c|c|c|}
\hline Ingredientes $(\mathrm{g} / \mathrm{kg})$ & Controle & $0,25 \%$ & $0,50 \%$ \\
\hline Milho & 555,77 & 550,10 & 544,81 \\
\hline Farelo de soja & 365,62 & 366,63 & 367,63 \\
\hline Calcário calcítico & 10,80 & 10,80 & 10,76 \\
\hline Fosfato bicálcico & 15,50 & 15,53 & 15,55 \\
\hline Sal & 4,55 & 4,82 & 4,83 \\
\hline Óleo vegetal & 38,90 & 40,77 & 42,60 \\
\hline Metionina & 1,68 & 1,69 & 1,69 \\
\hline Lisina & 2,18 & 2,16 & 2,13 \\
\hline Premix $^{1}$ & 5,00 & 5,00 & 5,00 \\
\hline Bentonita & 0,00 & 2,50 & 5,00 \\
\hline Total & 1000 & 1000 & 1000 \\
\hline \multicolumn{4}{|c|}{ Composição calculada } \\
\hline Energia metabolizável (kcal/kg) & 3050 & 3050 & 3050 \\
\hline Proteína bruta (\%) & 21,2 & 21,2 & 21,2 \\
\hline Cálcio total (\%) & 0,84 & 0,84 & 0,84 \\
\hline Fósforo disponível (\%) & 0,40 & 0,40 & 0,40 \\
\hline Sódio (\%) & 0,21 & 0,21 & 0,21 \\
\hline Potássio (\%) & 0,83 & 0,83 & 0,83 \\
\hline Cloro $(\%)$ & 0,32 & 0,34 & 0,34 \\
\hline Lisina digestível $(\%)$ & 1,22 & 1,21 & 1,22 \\
\hline Metionina digestível (\%) & 0,47 & 0,47 & 0,47 \\
\hline Treonina digestível (\%) & 0,72 & 0,72 & 0,72 \\
\hline \multicolumn{4}{|c|}{ Composição analisada } \\
\hline Cálcio (\%) & 0,83 & 0,74 & 0,86 \\
\hline Fósforo $(\%)$ & 0,68 & 0,64 & 0,65 \\
\hline
\end{tabular}

${ }^{1}$ Composição do premix mineral e vitamínico (níveis por kg do produto): vitamina B12 3.000mcg, vitamina B6 $622 \mathrm{mg}$, ácido pantotênico $2.934,9 \mathrm{mg}$, niacina $7.500 \mathrm{mg}$, biotina $19 \mathrm{mg}$, vitamina B2 $1.125 \mathrm{mg}$, manganês $16.800 \mathrm{mg}$, zinco $13.000 \mathrm{mg}$, ferro $12.600 \mathrm{mg}$, iodo $250 \mathrm{mg}$, cobre $2.100 \mathrm{mg}$, selênio $75 \mathrm{mg}$, vitamina A $2.640 .000 \mathrm{UI} / \mathrm{kg}$, vitamina D3 638.000UI/kg, vitamina E 3.650UI/kg, vitamina K3 450mg, vitamina B1 502mg, ácido fólico 189mg, colistina $2.500 \mathrm{mg}$, BHT 0,80g, colina 86,67g.

No $22^{\circ}$ dia, duas aves de cada repetição foram sacrificadas por deslocamento cervical e, após, realizou-se a coleta das suas tíbias. Estas foram preparadas segundo as recomendações de Kim et al. (2004), sendo manualmente descarnadas, sem cozimento. Nos ossos limpos, individualmente, foi realizada pesagem ao ar $(\mathrm{g})$, pesagem em água $(\mathrm{g})$, aferição de comprimento $(\mathrm{mm})$ e largura $(\mathrm{mm})$, conforme a metodologia descrita por Zhang e Coon (1997). O volume ósseo foi calculado pelo seu peso úmido (peso em água), assumindo-se que a densidade da água era $1 \mathrm{~g} / \mathrm{cm}^{3}$ (medições realizadas em sala com temperatura ambiente média de $25^{\circ} \mathrm{C}$ ).
Comprimento e largura foram aferidos por paquímetro digital Digimess ${ }^{\circledR}(0,001 \mathrm{~mm})$. O índice de Seedor foi calculado pela divisão do peso do osso por seu comprimento (Seedor et al.,1991).

Findas as avaliações morfométricas, as tíbias foram secas em estufa de ventilação forçada e processadas para aferição de matéria mineral $(\%)$ e posterior leitura de cálcio e fósforo (\%), conforme metodologias descritas por Silva e Queiroz (2002). O teor de cálcio foi determinado em espectrofotômetro de absorção atômica PerlinElmer® (AAnalyst 200) a 422,7nm de 
comprimento de onda. O teor de fósforo foi determinado por espectrofotômetro colorimétrico digital Kasuaki ${ }^{\circledR}$ a $725 \mathrm{~nm}$ de comprimento de onda, sendo todas as amostras lidas em duplicata, considerando-se o valor médio entre as duas leituras.

Utilizou-se um delineamento inteiramente ao acaso, em que cada uma das três dietas contou com oito repetições de 12 aves. Os resultados foram analisados utilizando-se o PROC GLM (General Linear Model) do programa estatístico SAS (SAS Institute Inc., 2002). Os dados foram submetidos à análise de variância (5\%), e as médias testadas por meio de contrastes lineares.
O projeto foi submetido ao Comitê de Ética em Experimentação Animal da Udesc - Cetea e aprovado pelo protocolo ${ }^{\circ} 6297240316$.

\section{RESULTADOS E DISCUSSÃO}

A inclusão de bentonita na dieta de frangos de corte não alterou $(\mathrm{P}>0,05)$ o consumo de ração, o ganho de peso, o peso vivo e a conversão alimentar, independentemente da dose de inclusão $(0,25$ ou $0,50 \%)$, como descrito na Tab. 3.

Tabela 3. Peso médio inicial, consumo de ração, peso médio final, ganho de peso médio diário e conversão alimentar de frangos de corte recebendo dieta sem inclusão de adsorvente e com inclusão de 0,25 ou $0,50 \%$ de bentonita, de 14 a 21 dias de idade

\begin{tabular}{|c|c|c|c|c|c|c|c|}
\hline Variáveis & 0,0 vs. 0,25 & $P$ & 0,0 vs. 0,50 & $P$ & 0,25 vs. 0,50 & $P$ & CV (\%) \\
\hline $\begin{array}{l}\text { Peso médio } \\
\text { inicial }(\mathrm{g})\end{array}$ & 368 vs. 371 & NS & 368 vs. 372 & NS & 372 vs. 372 & NS & 2,07 \\
\hline $\begin{array}{l}\text { Consumo } \\
\text { (g/ave/dia) }\end{array}$ & 78,2 vs. 80,1 & NS & 78,2 vs. 79,1 & NS & 80,1 vs. 79,1 & NS & 6,85 \\
\hline $\begin{array}{l}\text { Peso médio } \\
\text { final }(\mathrm{g})\end{array}$ & 780 vs. 786 & NS & 780 vs. 785 & NS & 786 vs. 785 & NS & 2,89 \\
\hline $\begin{array}{l}\text { Ganho de peso } \\
\text { médio diário }(\mathrm{g})\end{array}$ & 58,9 vs. 59,2 & NS & 58,9 vs. 59,0 & NS & 59,2 vs. 59,0 & NS & 4,24 \\
\hline $\begin{array}{c}\text { Conversão } \\
\text { alimentar (g/g) }\end{array}$ & 1,33 vs. 1,35 & NS & 1,33 vs. 1,34 & NS & 1,35 vs. 1,34 & NS & 5,30 \\
\hline
\end{tabular}

Outros autores confirmam os resultados obtidos alegando que os adsorventes não alteram o desempenho zootécnico das aves, uma vez que a inclusão de $0,5 \%$ de bentonita na dieta não afeta o consumo de ração, o ganho de peso e a conversão alimentar de frangos de corte criados até 42 dias de idade (Lopes et al., 2006). Doses mais elevadas $(0,75$ e $1,0 \%)$ mantiveram inalteradas as variáveis de peso vivo e consumo de ração de frangos de corte criados até cinco semanas de idade (Indresh et al., 2013). Para Pasha et al. (2008), a inclusão de $0,5 \%$ de bentonita não alterou o consumo de ração e a conversão alimentar, porém o ganho de peso foi superior, possivelmente em virtude do maior tempo de retenção do alimento no intestino, o que submeteu os nutrientes à ação enzimática por maior tempo.

Os níveis dos minerais séricos cálcio, cloretos, ferro e magnésio (Tab. 4) não diferiram $(\mathrm{P}>0,05)$ entre as aves suplementadas ou não com bentonita na dieta. No entanto, os níveis de fósforo no sangue das aves que receberam $0,5 \%$ de bentonita foram inferiores $(\mathrm{P}<0,05)$ aos das aves que não receberam o adsorvente. Resultados semelhantes foram encontrados por Franciscato et al. (2006), que observaram que as doses isoladas de 0,3 e $0,5 \%$ de bentonita em dietas de frangos de corte não são capazes de alterar os níveis de cálcio e magnésio. 
Minerais séricos...

Tabela 4. Níveis dos minerais séricos cálcio, cloretos, ferro, fósforo e magnésio de frangos de corte recebendo dieta sem inclusão de adsorvente e com inclusão de 0,25 ou $0,50 \%$ de bentonita

\begin{tabular}{cccccccc}
\hline Variáveis & 0,0 vs. 0,25 & $P$ & 0,0 vs. 0,50 & $P$ & 0,25 vs. 0,50 & $P$ & CV $(\%)$ \\
\hline $\begin{array}{c}\text { Cálcio } \\
\text { (mg/dL) }\end{array}$ & $5,29 v s .5,10$ & $\mathrm{NS}$ & $5,29 v s .5,04$ & $\mathrm{NS}$ & $5,10 v s .5,04$ & $\mathrm{NS}$ & 9,49 \\
$\begin{array}{c}\text { Cloretos } \\
(\mathrm{mEq} / \mathrm{L})\end{array}$ & 100 vs. 101 & $\mathrm{NS}$ & 101 vs. 102 & $\mathrm{NS}$ & 101 vs. 102 & $\mathrm{NS}$ & 1,32 \\
$\begin{array}{c}\text { Ferro } \\
(\mu \mathrm{g} / \mathrm{dL})\end{array}$ & $109 v s .102$ & $\mathrm{NS}$ & $109 v s .116$ & $\mathrm{NS}$ & $102 v s .116$ & $\mathrm{NS}$ & 18,2 \\
$\begin{array}{c}\text { Fósforo } \\
(\mathrm{mg} / \mathrm{dL})\end{array}$ & 6,67 vs. 6,37 & $\mathrm{NS}$ & $6,67 v s .6,28$ & $*$ & $6,37 v s .6,28$ & $\mathrm{NS}$ & 5,30 \\
$\begin{array}{c}\text { Magnésio } \\
(\mathrm{mg} / \mathrm{dL})\end{array}$ & 2,16 vs. 2,17 & $\mathrm{NS}$ & 2,16 vs. 2,19 & $\mathrm{NS}$ & 2,17 vs. 2,19 & $\mathrm{NS}$ & 5,37 \\
\hline
\end{tabular}

Dados avaliados por meio de contrastes lineares.

$P$ : probabilidade; $\mathrm{CV}$ : coeficiente de variação.

NS: não significativo $(\mathrm{P}>0,05) ; *$ : $\mathrm{P}<0,05$.

Os resultados obtidos neste ensaio corroboram parcialmente aqueles encontrados por Eraslan et al. (2005), os quais indicaram que as doses de 0,25 e $0,50 \%$ de bentonita na dieta diminuem os níveis séricos de cálcio e fósforo de frangos de corte aos 15 dias de idade, sem alterarem os níveis de sódio, potássio e cloro, e, portanto, sugerem que o adsorvente possa se ligar irreversivelmente ao cálcio e ao fósforo, inibindo sua absorção no trato gastrointestinal. Os autores demonstraram ainda que as aflatoxinas reduzem os níveis dos minerais séricos cálcio e fósforo e que a inclusão de bentonita nas doses de $0,25 \mathrm{ou}$ $0,50 \%$ causa o mesmo efeito, todavia em níveis menores.

Apesar de não terem sido observadas diferenças significativas nos níveis de cálcio, pode-se ressaltar que, em relação ao tratamento sem inclusão de bentonita, os valores caem gradativamente nas dietas com 0,25 e $0,50 \%$ do mineral, estando à probabilidade próxima da significância $(\mathrm{P}=0,058)$, quando se contrastam as doses 0,0 vs. 0,50. Baixo teor plasmático de cálcio aumenta a síntese de 1,25-dihidroxicolecalciferol $\quad\left[1,25(\mathrm{OH})_{2} \mathrm{D}_{3}\right]$, desencadeando a secreção de PTH, que, por sua vez, aumenta a reabsorção renal de cálcio (Wideman, 1987), o que pode ser um mecanismo responsável pela manutenção dos níveis séricos normais, ainda que ocorra a adsorção do cálcio pela bentonita em nível intestinal.

A adsorção de fosfato pela bentonita já foi comprovada em soluções aquosas, na remoção de fósforo contaminante (Pawar et al., 2016). Sabe-se que a bentonita é um excelente adsorvente devido a sua afinidade por substâncias polares (Pasha et al., 2008); assim, o fosfato apresenta-se como molécula passível de adsorção, já que é utilizado pelos animais em formas, tais como $\mathrm{PO}_{4}^{3-}, \mathrm{HPO}_{4}^{2-}$ e $\mathrm{H}_{2} \mathrm{PO}_{4}^{-}$. Presume-se, portanto, que a bentonita adsorve o fosfato em nível intestinal, provocando a redução de sua concentração sérica. Os resultados encontrados indicam que a redução dos níveis de fósforo não foi capaz de causar a condição patológica de hipofosfatemia, visto que esta é considerada apenas com níveis sanguíneos inferiores a 5mg/dL (Schmidt et al., 2007).

Não foram observadas diferenças significativas ( $\mathrm{P}>0,05)$ nas variáveis de peso do osso ao ar, volume ósseo, comprimento, largura, índice de Seedor e relação cálcio e fósforo de tíbias das aves suplementadas com bentonita na dieta (Tab. 5). No entanto, observou-se que a matéria mineral $(\%)$ e o fósforo foram reduzidos $(\mathrm{P}<0,05)$ com a inclusão de 0,25 e $0,50 \%$ de bentonita.

Os resultados de matéria mineral divergem dos obtidos por Khanedar et al. (2012), os quais não encontraram diferenças nas cinzas $(45,8 \%)$ das tíbias de aves suplementadas com até 1,5\% de bentonita na dieta. Deve-se figurar que a manutenção dos níveis plasmáticos dos minerais é soberana sobre a mineralização óssea. Desse modo, uma vez que as concentrações dos minerais no sangue sejam reduzidas, ocorrerá à mobilização óssea, a fim de manter a homeostase, já que o osso é um depósito dinâmico de minerais (Araújo et al., 2012). 
Tabela 5. Variáveis ósseas, teor de matéria mineral, cálcio, fósforo e relação cálcio/ fósforo de tíbias de frangos de corte recebendo dieta com inclusão de 0,0, 0,25 e 0,50\% de bentonita

\begin{tabular}{|c|c|c|c|c|c|c|c|}
\hline Variáveis & 0,0 vs. 0,25 & $P$ & 0,0 vs. 0,50 & $P$ & 0,25 vs. 0,50 & $P$ & $\mathrm{CV}(\%)$ \\
\hline $\begin{array}{l}\text { Peso do osso ao } \\
\text { ar (g) }\end{array}$ & 3,98 vs. 3,98 & NS & 3,98 vs. 4,15 & NS & 3,98 vs. 4,15 & NS & 9,21 \\
\hline Volume ósseo & 3,96 vs. 4,24 & NS & 3,96 vs. 4,13 & NS & 4,24 vs. 4,13 & NS & 9,28 \\
\hline $\begin{array}{l}\text { Comprimento } \\
\text { (mm) }\end{array}$ & 62,6 vs 63,6 & NS & 62,6 vs. 62,5 & NS & 63,6 vs. 62,5 & NS & 2,38 \\
\hline Largura (mm) & 5,75 vs 5,94 & NS & 5,75 vs. 5,97 & NS & 5,94 vs. 5,97 & NS & 7,00 \\
\hline Índice de Seedor & 0,06 vs. 0,06 & NS & 0,06 vs. 0,06 & NS & 0,06 vs. 0,06 & NS & 8,15 \\
\hline $\begin{array}{c}\text { Matéria mineral } \\
(\%)\end{array}$ & $43,3 v s .43,2$ & NS & 43,3 vs. 41,5 & $* *$ & 43,2 vs. 41,5 & $* *$ & 2,97 \\
\hline $\begin{array}{l}\text { Matéria mineral } \\
\qquad(\mathrm{g})\end{array}$ & 0,31 vs. 0,30 & NS & 0,31 vs. 0,28 & $*$ & 0,30 vs. 0,28 & NS & 9,57 \\
\hline Cálcio (\%) & 14,8 vs. 14,6 & NS & 14,8 vs. 13,9 & $*$ & 14,6 vs 13,9 & NS & 6,19 \\
\hline Fósforo (\%) & 5,46 vs. 5,35 & NS & 5,46 vs. 5,00 & $* *$ & 5,35 vs 5,00 & $*$ & 6,55 \\
\hline Relação Ca/P & 2,71 vs. 2,73 & NS & 2,71 vs. 2,78 & NS & 2,73 vs 2,78 & NS & 7,12 \\
\hline
\end{tabular}

Dados avaliados por meio de contrastes lineares.

$P$ : probabilidade; $\mathrm{CV}$ : coeficiente de variação.

NS: não significativo $(\mathrm{P}>0,05)$; *: $\mathrm{P}<0,05 ; * *$ : $\mathrm{P}<0,01 ; * * *: \mathrm{P}<0,001$

A maioria dos trabalhos apresenta os resultados de cinzas ósseas expressos em porcentagem, porém Li et al. (2015) apresentam uma discussão plausível em relação aos pesos relativos e absolutos de matéria mineral óssea. Os autores afirmam que a expressão de peso das cinzas reflete a quantidade de mineral contida no osso, a qual é afetada tanto pelo tamanho ósseo quanto pela mineralização óssea, podendo expressar melhor as quantidades de cálcio e fósforo depositados nos ossos associadas a aves de maior peso e/ou tamanho ósseo, enquanto a expressão em porcentagem elimina as diferenças entre pesos ósseos observadas entre tratamentos, sendo menos precisa para determinar os impactos dietéticos na mineralização óssea.

Com base no exposto, avaliou-se também o peso das cinzas $(\mathrm{g})$, constatando-se que a inclusão de $0,5 \%$ de bentonita na dieta foi capaz de reduzir essa variável $(\mathrm{P}<0,05)$, o que confirma os dados obtidos em porcentagem, fornecendo, assim, maior coesão ao presumir-se que as alterações no metabolismo mineral causadas pela presença da bentonita em nível intestinal induzem a mobilização de minerais ósseos.

O peso da matéria mineral dos ossos é um indicador de reservas minerais, sendo diretamente afetado pela dieta, contudo também é influenciado pela medula, pela cartilagem e pelo periósteo (Field, 2000). Os principais íons que compõem a matriz mineral óssea na forma de cristais de hidroxiapatita são o fosfato e o cálcio (Araújo et al., 2011) e, portanto, a mobilização óssea desses minerais implicará diretamente o teor de cinzas ósseas.

Presume-se que a menor absorção entérica do fósforo, causada pela adsorção da bentonita, induz a redução nos níveis plasmáticos do mineral e, consequentemente, a mobilização óssea, com o intuito de manter a fosfatemia. Baixas concentrações plasmáticas levam à síntese renal da forma ativa da vitamina $\mathrm{D}$, que, por sua vez, tende a aumentar a absorção entérica e a reabsorção renal do mineral, ao mesmo tempo em que a reabsorção óssea é induzida com o objetivo de manter as concentrações plasmáticas de fósforo em níveis normais (ProszkowiecWeglarz; Angel, 2013). A redução no teor de fósforo afeta diretamente o teor de cinzas ósseas, já que, embora o fósforo esteja presente em todos os tecidos, seu principal estoque encontra-se nos ossos, que albergam aproximadamente $85 \%$ do fósforo total do organismo (Hamdi et al., 2015).

O teor de cálcio também sofreu redução $(\mathrm{P}<0,05)$, porém somente na maior dose testada $(0,5 \%)$. Apesar de a diferença no teor de cálcio e fósforo das tíbias das aves que receberam a dieta 
controle e das que ingeriram $0,5 \%$ de bentonita ser de aproximadamente 1 e $0,5 \%$, respectivamente, esta já é capaz de alterar a mineralização óssea, reduzindo o teor de cinzas (Hamdi et al., 2015). Em virtude da alta exigência de cálcio, é provável que seus mecanismos reguladores sejam mais efetivos que os demais minerais, buscando manter a homeostase, fato que se torna mais expressivo nas linhagens modernas de aves de corte de crescimento rápido e alta deposição muscular, que exigem do sistema locomotor grande capacidade de sustentação (Araujo et al., 2011).

Deve-se atentar ao fato de que a redução na matéria mineral óssea observada pode não estar relacionada somente à redução dos teores de cálcio e fósforo, mas sim a outros minerais que podem estar envolvidos no processo de adsorção em nível intestinal pela bentonita, tendo sua absorção limitada e sofrendo, consequentemente, uma mobilização óssea, haja vista a manutenção da homeostase. A inclusão de $0,5 \%$ de montmorilonita cálcica na dieta de frangos de corte não alterou os depósitos de cálcio, fósforo, cobre, ferro e zinco nos ossos, porém o conteúdo de manganês, chumbo e flúor foi diminuído (Desheng et al., 2005). Alguns autores justificam as diferenças encontradas nos trabalhos pela diversidade dos aluminossilicatos utilizados (Khanedar et al., 2012).

O índice de Seedor foi calculado, pois é um indicador de densidade óssea e quanto maior o seu valor, mais denso é o osso (Ebrahimi et al., 2016). As alterações encontradas na concentração de minerais e a ausência de diferenças nas variáveis relacionadas à resistência à quebra são coerentes, já que a resistência à quebra está mais relacionada às concentrações de proteínas colagenosas e não colagenosas do que a concentração de minerais propriamente (Araujo et al., 2011). Esse resultado já foi confirmado por outros autores, que verificaram que maiores teores de cinzas ósseas e fósforo nas tíbias de frangos de corte em fase de crescimento não resultaram em maior resistência à quebra (Runho et al., 2001), devendo a desmineralização óssea ser prolongada para induzir a perda de resistência à quebra.

$\mathrm{Na}$ avicultura industrial, os problemas locomotores são frequentes e responsáveis por grandes perdas econômicas, além de atentarem contra o bem-estar das aves. São mais recorrentes em machos, principalmente ao final da fase de crescimento, sendo justificados pela alta deposição muscular e pelo rápido desenvolvimento das aves. Uma vez que transtornos esqueléticos são provocados por alterações no processo de crescimento e homeostase (Araújo et al., 2012), trabalhos futuros poderiam investigar a possível correlação entre desordens esqueléticas e a presença de bentonita na dieta, já que, no presente trabalho, o adsorvente demonstrou contribuir para a piora da mineralização óssea.

\section{CONCLUSÃO}

Conclui-se que a inclusão de até $0,50 \%$ do adsorvente de micotoxinas bentonita na dieta de frangos de corte não altera o desempenho zootécnico das aves. A inclusão de $0,25 \%$ de bentonita, na dieta de frangos de corte, não altera a concentração dos minerais séricos e a deposição de minerais nas tíbias. No entanto, a inclusão de $0,5 \%$ reduz os níveis séricos de fósforo, o teor de matéria mineral e a concentração de cálcio e fósforo ósseos, sem afetar as características morfométricas ósseas.

\section{REFERÊNCIAS}

ARAÚJO, G.M. et al. Variação aniônica da dieta sobre características ósseas de frangos de corte: resistência à quebra, composição orgânica e mineral. Arq. Bras. Med. Vet. Zootec., v.63, p.954-961, 2011.

ARAÚJO, G.M.; VIEITES, F.M.; SOUZA, C.S. Importância do desenvolvimento ósseo na avicultura. Arch. Zootec., v.61, p.79-89, 2012.

BRYDEN, W.L. Mycotoxin contamination of the feed supply chain: implication for

DESHENG, Q.; FAN, L.; YANHU, Y.; NIYA, Z. Adsorption of aflatoxin B1 on montmorillonite. Poult. Sci., v.84, p.959-961, 2005.

EBRAHIMI, H.; SHARIATMADARI, F.; KARIMI TORSHIZI, M.A. Dietary supplementation and in ovo injection of $1 \alpha-\mathrm{OHD} 3$ in a low-calcium and lowphosphorous diets for broilers. J. Appl. Anim. Res., v.44, p.113-117, 2016.

ERASLAN, G. et al. The effects of aflatoxin and sodium bentonite combined and alone on some blood electrolyte levels in broiler chickens. Turk. J. Vet. Anim. Sci., v.29, p.601-605, 2005. 
FIELD, R.A. Ash and calcium as measures of bone in meat and bone mixtures. Meat Sci., v.55, p.255-264, 2000 .

FRANCISCATO, C. et al. Concentrações séricas de minerais e funções hepática e renal de frangos intoxicados com aflatoxina e tratados com montmorilonita sódica. Pesqui. Agropecu. Bras., v.41, p.1573-1577, 2006.

GOWDA, N.K.S.; SWAMY, H.V.L.N.; MAHAJAN P. Recent advances for control, counteraction and amelioration of potential aflatoxins in animal feeds. In: RAZZAGHI-ABYANEH, M. Aflatoxins - recent advances and future prospects. Rijeka, Croatia: InTech, 2013. p.59-62.

GROSICKI, A.; KOWALSKI, B.; BIK, D. Influence of bentonite on trace element kinetics in rats. 2. Calcium. Bull. Vet. Inst. Pulawy, v.48, p.337-340, 2004.

HAMDI, M. et al. Effect of different levels of calcium and phosphorus and their interaction on the performance of young broilers. Poult. Sci., v.94, p.2144-2151, 2015. HWANG, J.H.; LEE, K.G. Reduction of afl atoxin B1 contamination on wheat by various cooking treatments. Food Chem., v.98, p.7175, 2006.

INDRESH, H.G.; DEVEGOWDA， G.; WILFRED RUBAN, S.; SHIVAKUMAR, M.C. Effects of high grade bentonite on performance, organ weights and serum biochemistry during aflatoxicosis in broilers. Vet. World, v.6, p.313-317, 2013.

KHANEDAR, F.; VAKILI, R.; ZAKIZADEH, S. Effects of two kinds of bentonite on the performance, blood biochemical parameters, carcass characteristics and tibia ash of broiler chicks. Global Vet., v.9, p.720$725,2012$.

KIM, W.K. et al. Effects of different bone preparation methods (fresh, dry, and fat-free dry) on bone parameters and the correlations between bone breaking strength and the other bone parameters. Poult. Sci., v.83, p.1663-1666, 2004.

LI, W. et al. Impact of response criteria (tibia ash weight vs. percent) on phytase relative non phytate phosphorus equivalance. Poult. Sci., v.94, p.22282234,2015 .

LOPES, J.M.; RUTZ, F.; MALLMANN, C.A.; TOLEDO, G.S.P. Adição de bentonita sódica como adsorvente de aflatoxinas em rações de frangos de corte. Ciênc. Rural, v.36, p.1594-1599, 2006.

MAZIERO, M.T.; BERSOT, L.S. Micotoxinas em alimentos produzidos no Brasil. Rev. Bras. Prod. Agroind., v.12, p.89-99, 2010.
PASHA, T.N. et al. The effect of feed supplemented with different sodium bentonite treatments on broiler performance. Turk. J. Vet. Anim. Sci., v.32, p.245-248, 2008.

PAWAR, R.R. et al. Al-intercalated acid activated bentonite beads for the removal of

PROSZKOWIEC-WEGLARZ， M.; ANGEL, R. Calcium and phosphorus metabolism in broilers: effect of homeostatic mechanism on calcium and phosphorus digestibility. J. Appl. Poult. Res., v.22, p.609-627, 2013

ROSTAGNO, H.S. et al. Tabelas brasileiras para aves e suínos: composição de alimentos e exigências nutricionais. 3.ed. Viçosa: Universidade Federal Viçosa, 2011. 252p.

RUNHO, R.C. et al. Exigência de fósforo disponível para frangos de corte machos e fêmeas de 1 a 21 dias de idade. Rev. Bras. Zootec., v.30, p.187-196, 2001.

SAKOMURA, N.K.; ROSTAGNO, H.S. Métodos de pesquisa em nutrição de monogástricos. Jaboticabal: Funep, 2007. 283p.

SAS user's guide: statistics, version 9.0. Cary: SAS, 2002

SCHMIDT, E.M.S.; LOCATELLI-DITTRICH， R.; SANTIN, E. PAULILLO, A.C. Patologia clínica em aves de produção - uma ferramenta para monitorar a sanidade avícola - revisão. Arch. Vet. Sci., v.12., p.920, 2007.

SEEDOR, J.G.; QUARRUCCIO, H.A.; THOMPSON, D.D. The bisphosphonate alendronate (MK-217) inhibits bone loss due to ovariectomy in rats. J. Bone Miner. Res., v.6, p.339-346, 1991.

SILVA, D.J.; QUEIROZ, A.C. Análise de alimentos: métodos químicos e biológicos. Viçosa: UFV, 2002. 235p.

SOUTHERN, L.L.; WARD, T.L.; BIDNER, T.D.; HEBERT, L.G. Effect of sodium bentonite or hydrated sodium calcium aluminosilicate on growth performance and tibia mineral concentrations in broiler chicks fed nutrient-deficient diets. Poult. Sci., v.73, p.848-854, 1994.

WIDEMAN JR., R.F. Renal regulation of avian calcium and phosphorus metabolism. J. Nutr., p.808815,1987

ZHANG, B.; COON, C.N. The relationship of various tibia bone measurements in hens. Poult. Sci., v.76, p.1698-1701, 1997. 